Reprod. Nutr. Dévelop., 1988, 28 (1), 171-172.

\title{
Composition en acides aminés des aliments et des résidus de fermentation in vitro
}

M. ANTONGIOVANNI, F. GRIFONI

Dipartimento di Scienze Zootecniche, Via delle Cascine, 5, 50144 Firenze, Italie.

Summary. This paper proposes a quite simple technique based on aminoacid analysis of feed samples, before and after in vitro fermentation with rumen inoculum, and of the faeces relative to an in vivo digestibility trial run on the same feeds. Its aim is the estimation of the potential nutritive value of proteins for ruminant animals.

Nous recherchons une méthode simple de la prévision des protéines digestibles dans l'intestin grêle, basée sur la comparaison entre les compositions en acides aminés des aliments, des résidus de fermentation in vitro comme l'ont fait Dennison et Philips (1983) et des fèces. Pour des raisons de place, nous nous limitons à présenter ici une partie des résultats obtenus pour 6 aliments (fig. 1) des 19 que nous avons étudiés.

Matériel et méthodes. Les aliments ont été soumis à une fermentation in vitro pendant $48 \mathrm{~h}$ en présence de liquide de rumen, selon la méthode de Tilley et Terry (1963) limitée à la $1^{\text {re }}$ phase. Les acides aminés ont été déterminés par chromatographie après hydrolyse par $\mathrm{HCl} 6 \mathrm{~N}$ pendant $24 \mathrm{~h}$ sur les aliments et sur le résidu total présent dans les tubes après la fermentation.

Résultats et discussion. La digestibilité de l'azote mesurée sur des moutons varie en sens inverse de la teneur en azote. La proportion de l'azote total recouvrée dans les 16 acides aminés dosés est moins variable dans les résidus de fermentation (67 à $76 \%$ ) que dans les aliments (68 à $87 \%$ ).

Les proportions des différents acides aminés sont assez voisines dans les trois fourrages sensu stricto et plus variables dans les trois aliments dont les protéines proviennent surtout de grains ou de graines (fig. 1). Ces proportions sont beaucoup moins variables dans les résidus de fermentation. Ce peut être dû à une certaine similitude dans la composition des protéines non dégradées et/ou à la présence de protéines bactériennes. Les protéines des résidus de fermentation sont dans l'ensemble plus riches en lysine, thréonine, méthionine, isoleucine, phénylalanine que les aliments (fig. 1).

Cette méthode d'étude permet de mieux connaître la qualité des protéines alimentaires non dégradées dans le rumen qui vont être digérées dans l'intestin grêle. 

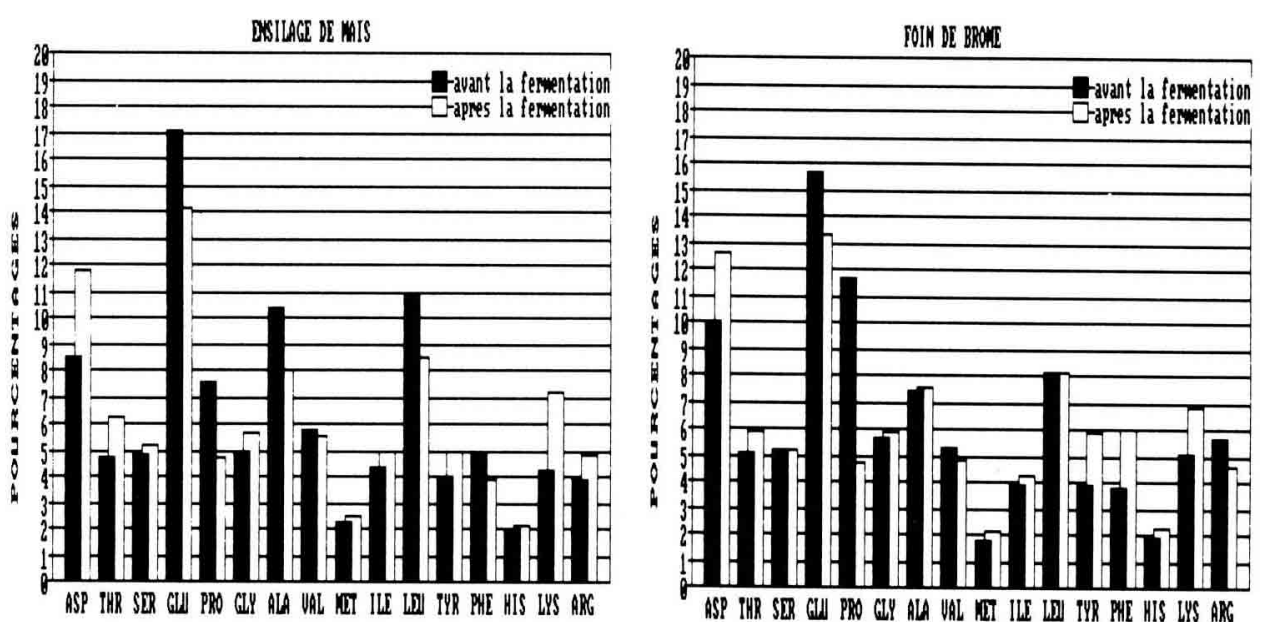
ALINDOA COPPSE"
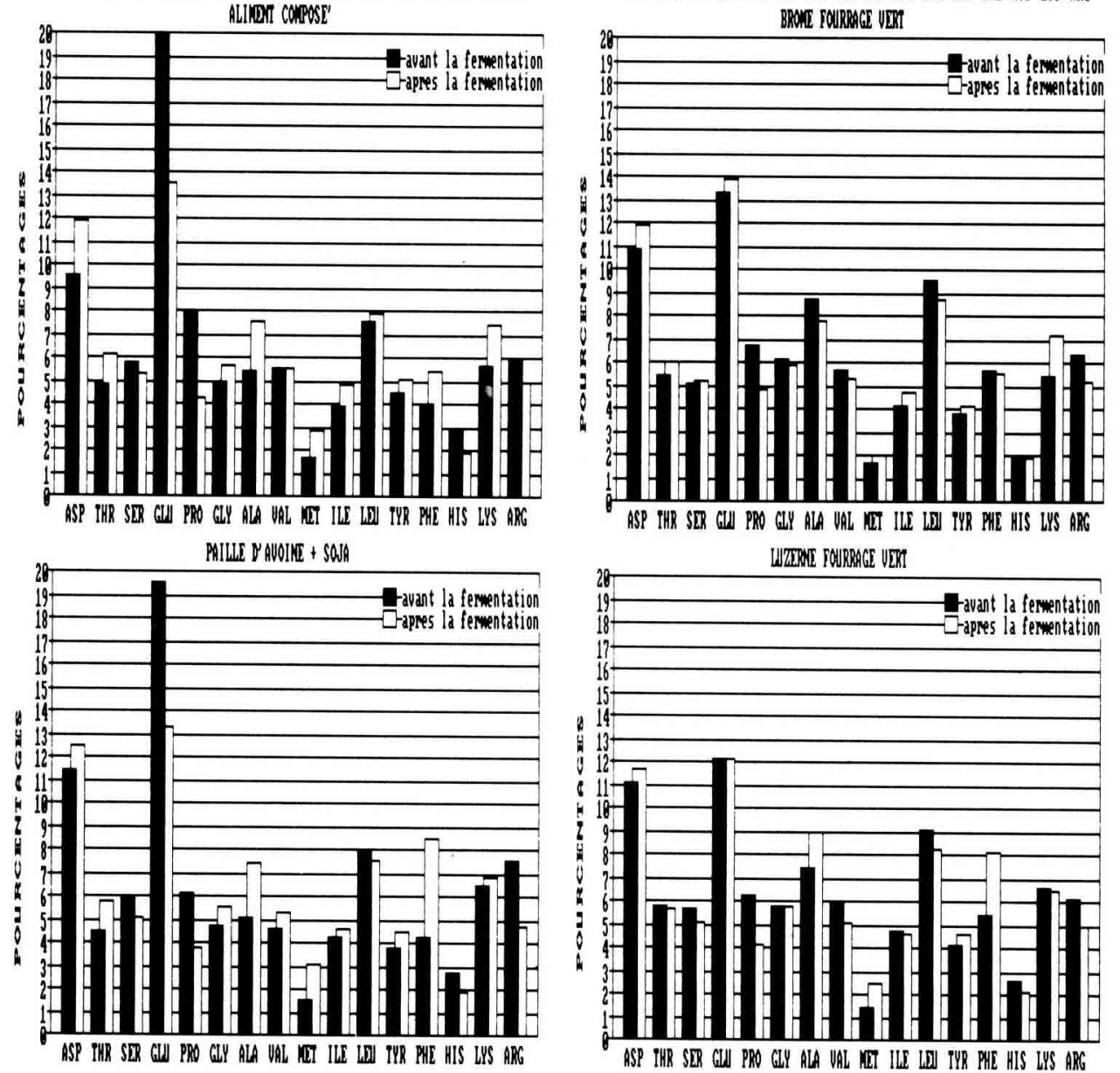

FIG. 1. - Acides aminés des aliments avant et après la fermentation. 